\title{
Analysis of Hemodialysis-Associated Hypoglycemia in Patients with Type 2 Diabetes Using a Continuous Glucose Monitoring System
}

\author{
Hye Seung Jung, M.D., Ph.D., Hong II Kim, M.D.,, ${ }^{1,2}$ Min Joo Kim, M.D., \\ Ji Won Yoon, M.D., ${ }^{1}$ Hwa Young Ahn, M.D., Y' Young Min Cho, M.D., Ph.D., \\ Kook-Hwan Oh, M.D., Ph.D., ${ }^{3}$ Kwon Wook Joo, M.D., Ph.D., ${ }^{3}$ Jung Geon Lee, M.D., Ph.D., \\ Seong Yeon Kim, M.D., Ph.D., and Kyong Soo Park, M.D., Ph.D.,2
}

\begin{abstract}
Background: Adequate glycemic control is important for patients with end-stage renal disease on maintenance hemodialysis (HD). Continuous glucose monitoring (CGM) systems are reported as a useful method for glucose monitoring in patients under maintenance HD. The object of this study was to describe glucose profiles and hypoglycemia associated with HD in diabetes patients using a CGM system.

Methods: We recruited nine medically stable patients with type 2 diabetes under maintenance HD. CGMS ${ }^{\circledR}$ System Gold ${ }^{\mathrm{TM}}$ (Medtronic MiniMed, Northridge, CA) was applied to the subjects for $144 \mathrm{~h}$. During the period, HD using glucose-containing dialysate was performed every other day. Various glucose profiles were calculated from the CGM readings and compared between the day on and the day off dialysis.

Results: Mean \pm SD for age, duration of diabetes, and hemoglobin A1c were $67 \pm 9$ years, $24 \pm 9$ years, and $8.6 \pm 1.2 \%$, respectively. Hemoglobin A1c was correlated with mean glucose $(\rho=0.780, P<0.05)$ and with area under the curve for glucose above $180 \mathrm{mg} / \mathrm{dL}(\rho=0.797, P<0.05)$. Although there was no difference for mean amplitude of glycemic excursion between the day on and off HD, hypoglycemia occurred predominantly with day on HD. In the subjects who maintained antidiabetes agents with day on HD, glucose levels decreased with initiation of HD, causing significantly lower glucose levels compared to those during the equivalent time of the following day without HD.

Conclusions: According to the CGM system, glucose variability was not affected by HD. However, in spite of glucose-containing dialysate, HD seemed to increase the risk of hypoglycemia.
\end{abstract}

\section{Background}

$\mathbf{T}$ HE MOST COMMON CAUSE of end-stage renal disease (ESRD) is diabetes in the United States, ${ }^{1}$ and so will it be in Asian countries, because of the sharp rise of diabetes in the region. ${ }^{2}$ Therefore, those who have ESRD and are receiving maintenance hemodialysis (HD) are usually exposed to other complications of diabetes, too. Chronic diabetes complications result from hyperglycemia, ${ }^{3,4}$ but glucose variability and hypoglycemia are additional components of diabetes morbidity. 5 Cardiac disease is the leading cause of mortality among patients undergoing HD. ${ }^{1}$ Hyperglycemia was reported to be strongly associated with sudden cardiac death in
HD patients with type 2 diabetes, which accounted for increased cardiovascular events and mortality. ${ }^{7}$ In the meantime, hypoglycemia is also fatal, especially in the presence of cardiovascular diseases. ${ }^{4}$ Although there is no evidencebased guideline for the glycemic targets for hemodialysed patients with type 2 diabetes, adequate glycemic control in those population seems to be a predictor of survival ${ }^{8}$ and should be in need of more attention than ever.

ESRD patients are not only insulin resistant but also prone to hypoglycemia because of impaired renal gluconeogenesis, malnutrition, altered pharmacokinetics of insulin, and hypoglycemic agents. ${ }^{9,10}$ In addition, HD itself can induce hypoglycemia, the underlying mechanism of which has not been

Divisions of ${ }^{1}$ Endocrinology and Metabolism and ${ }^{3}$ Nephrology, Department of Internal Medicine, Seoul National University College of Medicine, Seoul, Republic of Korea.

${ }^{2}$ Department of Molecular Medicine and Biopharmaceutical Sciences, Graduate School of Convergence Science and Technology, Seoul National University, Seoul, Republic of Korea.

${ }^{4}$ Namseoul Medical Clinic \& Dialysis Unit, Seoul, Republic of Korea. 
established. ${ }^{11}$ Although the risk of hypoglycemia could be reduced by use of glucose-added dialysis fluid, ${ }^{12,13}$ glycemic patterns are still hardly predictable, making it difficult to control blood glucose levels without a risk of hypoglycemia.

Continuous glucose monitoring (CGM) systems have been validated to be beneficial and are recommended in a subset of diabetes patients by the American Diabetes Association. ${ }^{14,15}$ Recently, CGM was shown to provide glycemic information in patients with type 2 diabetes mellitus undergoing HD, too. ${ }^{16,17}$ Therefore, if a CGM system can be effectively adapted, we might prevent both hypoglycemia and hyperglycemia causing high mortality in diabetes patients undergoing HD.

In this study, we described the glucose profiles, occurrence of hypoglycemia, and usefulness of a CGM device in maintenance-hemodialysed patients with type 2 diabetes. These results can suggest better antidiabetes regimens for patients under similar circumstances.

\section{Subjects and Methods}

This study was approved by the Institutional Review Board of Seoul National University Hospital, Seoul, Republic of Korea, and written informed consent was obtained from all the subjects.

\section{Participants and laboratory analysis}

Nine subjects with type 2 diabetes and ESRD who were clinically stable and were undergong maintenance HD for more than 2 months were recruited. Some of them were using insulin. Their blood glucose levels were monitored regularly, but a CGM system had not been applied (Table 1). HD was performed for $3 \mathrm{~h}$ three times per week, and the dialytic solution contained $100-200 \mathrm{mg} / \mathrm{dL}$ glucose. A history of cardiovascular disease, including ischemic heart disease, cerebrovascular disease, or peripheral vascular disease, and retinopathy due to diabetes mellitus were established through history taking and medical records. Fasting blood samples were taken for measurement of hemoglobin A1c (HbA1c) using Diabetes Control and Complications Trial-aligned high-performance liquid chromatography (Variant ${ }^{\circledR}$ II Turbo,

Table 1. Baseline Characteristics of Participants

\begin{tabular}{lc}
\hline Characteristic & Value \\
\hline Age (years) & $67 \pm 9$ \\
Sex ratio (male:female) & $1: 2$ \\
BMI (kg/m²) & $23.3 \pm 3.5$ \\
Waist circumference (cm) & $85.9 \pm 7.8$ \\
DM duration (years) & $24 \pm 9$ \\
HD duration (years) & $5 \pm 5$ \\
BUN (mg/dL) & $45 \pm 15$ \\
Hb (g/dL) & $11.3 \pm 1.3$ \\
HbA1c (\%) & $8.6 \pm 1.2$ \\
CVD (numbers) & 4 \\
DM retinopathy (none:NPDR:PDR) & $1: 1: 7$ \\
Medication (insulin:OAD:combined) & $5: 2: 2$ \\
\hline
\end{tabular}

Data are mean $\pm S D$ values.

BMI, body mass index; BUN, blood urea nitrogen; CVD, cardiovascular disease; $\mathrm{DM}$, diabetes mellitus; $\mathrm{Hb}$, hemoglobin; $\mathrm{HbA1c}$, hemoglobin A1c; HD, hemodialysis; NPDR, nonproliferative diabetic retinopathy; OAD, oral antidiabetes drug; PDR, proliferative diabetic retinopathy.
Bio-Rad, Hercules, CA) (normal values, 4.0-6.4\%), hemoglobin (Sysmex XE-2100 autoanalyzer, Sysmex, Kobe, Japan), and blood chemistry (Hitachi 7600 autoanalyzer, Hitachi, Tokyo, Japan).

\section{CGM and diaries}

A 72-h CGM system $\left(\right.$ CGMS $^{\circledR}$ System Gold ${ }^{\mathrm{TM}}$, Medtronic MiniMed, Northridge, CA) was used in this study. This system has been described in detail elsewhere. ${ }^{18,19}$ In brief, it is a Holter-type device with a sensor having a glucose oxidasebased platinum electrode. The sensor is inserted into the subcutaneous tissue of the anterior abdominal wall, where the glucose oxidase catalyzes the oxidation of glucose in the interstitial fluid, which generates an electrical current. The current is carried to a pager-sized monitor that analyzes the data every $10 \mathrm{~s}$ and stores a smoothed average over $5 \mathrm{~min}$. The range of interstitial glucose range is $40-400 \mathrm{mg} / \mathrm{dL}$, and each sensor is used continuously for up to $72 \mathrm{~h}$. In various studies on the device accuracy compared with reference serum/ blood glucose levels in subjects with diabetes, the correlation coefficiency range was 0.8-0.9, and mean absolute differences were $11-16 \% .^{20-23}$ The subjects were educated to calibrate the system using capillary blood glucose tests four times a day and to record the time and amounts of meals, snacks, medications, exercise, and episodes of hypoglycemia during the study period. After the device was applied to each patient twice in succession for 144 consecutive $h$ by a trained nurse, the data were downloaded using MiniMed Solutions Software version 2.0b.

\section{Calculation of glucose profiles}

We defined the first $24 \mathrm{~h}$ from the start of HD as day on dialysis (HD-on) and the next $24 \mathrm{~h}$ as day off dialysis (HD-off). The following variables were calculated from CGM readings in each subject day on and off dialysis, respectively:

- Mean glucose. CGM measures at 5-min intervals were averaged for $24 \mathrm{~h}$.

- Mean postmeal maximum glucose (MPMG). Highest CGM measures in the postprandial $4 \mathrm{~h}$ were averaged during the study period.

- Area under the curve above $180 \mathrm{mg} / \mathrm{dL}$ (AUC180). The area under the curve for CGM measures above $180 \mathrm{mg} / \mathrm{dL}$ was calculated.

- Mean amplitude of glucose excursions (MAGE). The means and SDs of glucose for HD-on and HD-off were calculated. The peak was defined as CGM measures increased and then decreased more than $1 \mathrm{SD}$, and the nadir was CGM measures decreased and then increased more than $1 \mathrm{SD}$, respectively. MAGE was the mean of absolute difference of peak-to-nadir or nadir-to-peak direction. The details for calculation of MAGE have been described previously. ${ }^{24}$

- Hypoglycemia. Hypoglycemia was defined as a CGM reading $<80 \mathrm{mg} / \mathrm{dL}$ for $\geq 20 \mathrm{~min}$. Frequency and duration of hypoglycemia were counted.

\section{Analysis of food diaries}

Food diaries were analyzed by a registered dietitian. Total calorie intake and carbohydrate intake were calculated using CAN-Pro software version 3.0 (The Korean Nutrition Society, Seoul, Republic of Korea). ${ }^{25}$ 


\section{Statistical analysis}

All data are expressed as mean \pm SD values and were analyzed using SPSS software version 11.0 (SPSS Inc., Chicago, IL). For comparisons between HD-on and HD-off, Wilcoxon signed ranks test and repeated-measures analysis of variance were applied. For correlation analysis, Spearman's $\rho$ was calculated. The level of significance was defined as $P<0.05$.

\section{Results}

\section{Baseline characteristics of participants (Table 1)}

Most of the nine subjects with type 2 diabetes who were undergoing maintenance HD had diabetes complications other than nephropathy, and blood glucose control was not adequate $(\mathrm{HbA} 1 \mathrm{c}, 8.6 \pm 1.2 \%)$. To prevent hypoglycemia, five of the nine patients reduced doses of insulin or oral antidiabetes drugs before HD (dose reduction by $36 \pm 13 \%$ /day, Table 2).

\section{Associations between $\mathrm{HbA1C}$ and CGM measurements in hemodialysed patients}

Results of correlation analysis between $\mathrm{HbA} 1 \mathrm{c}$ and mean glucose levels were statistically significant. Indices of postprandial hyperglycemia such as AUC180 and MPMG were
Table 2. Details of Medications

\begin{tabular}{|c|c|c|c|}
\hline $\begin{array}{l}\text { Patient } \\
\text { number }\end{array}$ & Day off HD & $\begin{array}{c}\text { Dose reduction } \\
\text { for day } \\
\text { on } H D(\%)\end{array}$ & Hypoglycemia \\
\hline 1 & $\begin{array}{l}\text { Nateglinide } 45 \mathrm{mg} \text { tid; } \\
\text { glimepiride } 2 \mathrm{mg} \text { gd }\end{array}$ & 0 & Yes \\
\hline 2 & NPH 27 units/day & 22 & Yes \\
\hline 3 & $\begin{array}{l}\text { Nateglinide } 120 \mathrm{mg} \text { tid; } \\
\text { NPH } 6 \text { units/day }\end{array}$ & 33 & No \\
\hline 4 & MSII 28 units/day & 29 & Yes \\
\hline 5 & RI 8 units/day & 50 & No \\
\hline 6 & NPH 16 units/day & 0 & No \\
\hline 7 & Gliclazide $80 \mathrm{mg}$ bid & 50 & Yes \\
\hline 8 & MSII 55 units/day & 0 & Yes \\
\hline 9 & $\begin{array}{l}\text { Acarbose } 50 \mathrm{mg} \text { bid; } \\
\text { NPH } 18 \text { units/day }\end{array}$ & 0 & No \\
\hline
\end{tabular}

bid, two times a day; HD, hemodialysis; MSII, multiple subcutaneous insulin injections; NPH, neutral protamine Hagedorn; qd, once a day; RI, regular insulin; tid, three times a day.

also related with $\mathrm{HbA1c}$ (Fig. 1A). In contrast, MAGE, an index of glucose variability, was not correlated with either HbA1c or other CGM calculations (Fig. 1B).
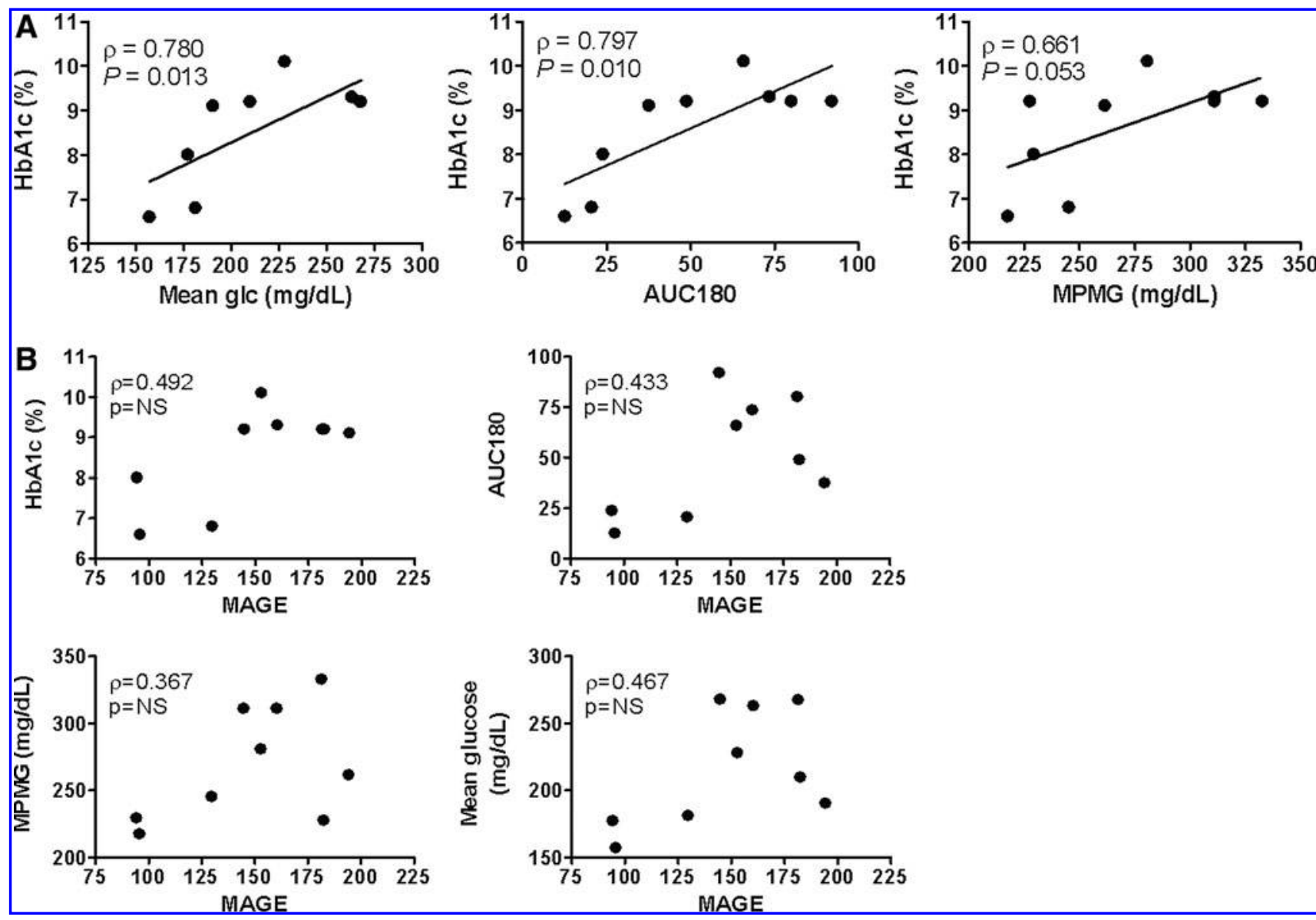

FIG. 1. (A) Correlation analysis between glucose profiles from continuous glucose monitoring readings and hemoglobin A1c (HbA1c). (B) Correlation analysis between mean amplitude of glucose excursions (MAGE) and other glucose profiles. The subjects were medically stable patients with type 2 diabetes mellitus undergoing chronic hemodialysis. AUC180, area under the curve above $180 \mathrm{mg} / \mathrm{dL}$; glc, glucose; MPMG, mean postmeal maximum glucose; NS, not significant. 


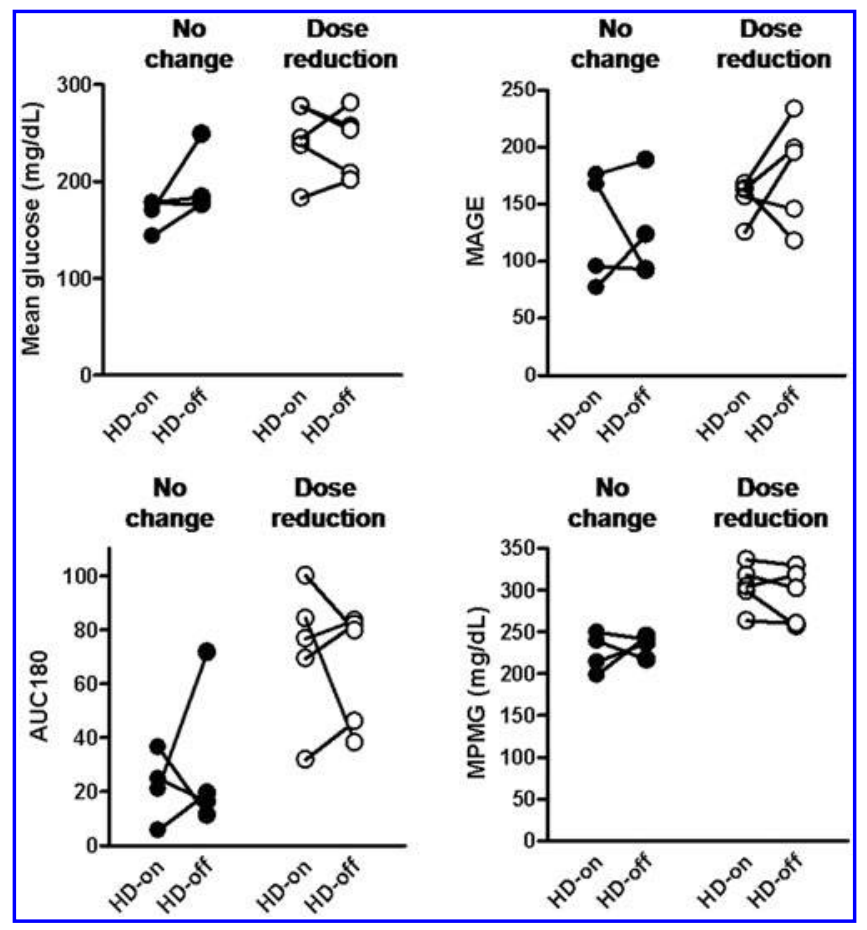

FIG. 2. No changes in glucose profiles between days on and off hemodialysis (HD-on and HD-off, respectively): mean glucose, mean amplitude of glucose excursions (MAGE), area under the curve above $180 \mathrm{mg} / \mathrm{dL}$ (AUC180), and mean postmeal maximum glucose (MPMG).

\section{Comparison of glycemic profiles from CGM measurements between $H D$-on and HD-off}

For each subject, we could collect at least 2 days of CGM readings HD-on and HD-off, respectively. When the averaged values were compared, glycemic patterns in each subject were not statistically different between HD-on and HD-off. Whether antidiabetes drugs for day on HD were reduced or not, there were no differences in mean glucose levels, MAGE, AUC180, and MPMG between HD-on and HD-off (Fig. 2).

\section{Occurrence of hypoglycemia}

During the study period, 10 hypoglycemia episodes defined as a CGM reading $<80 \mathrm{mg} / \mathrm{dL} \geq 20 \mathrm{~min}$ happened in five subjects, and $80 \%$ occurred in the day on HD. The lowest readings in each episode were $71,70,40,77,40,40,61,68,56$, and $54 \mathrm{mg} / \mathrm{dL}$. However, because the reading range of the CGM device was $40-400 \mathrm{mg} / \mathrm{dL}$, the values could be overestimated. Among these episodes, only three were associated with hypoglycemic symptoms and confirmed by capillary blood glucose tests. The other episodes were not associated with any symptoms, and the CGM device does not give realtime glucose values to the wearer; simultaneous capillary blood glucose tests were not performed. Regardless of medication reduction, frequency and duration of hypoglycemia were apparently predominant in the day on HD (Fig. 3). To examine if there is "a hot spot" of hypoglycemia, we determined duration and severity of hypoglycemia (Fig. 4A [width and height of each rectangle, respectively]) in the subjects who experienced hypoglycemia with day on dialysis. We found that major events usually occurred during the first $12 \mathrm{~h}$ of the day on HD. When the CGM readings of subjects were averaged, we also observed that glucose levels started to decrease with HD in the subjects whose medications were maintained ( $F=8.88, P<0.05$ of the enlarged graph in Fig. 4B), which caused a significant difference during the first $6 \mathrm{~h}$ between HD-on and HD-off ( $F=11.9, P<0.05$ in Fig. 4B). However, such results were not observed in the subjects who had reduced medications for the day on dialysis (Fig. 4C).

\section{Dietary analysis}

A food diary was completed by eight subjects. A difference of carbohydrate intake between HD-on and HD-off was observed with marginal significance (HD-on, 261.7 $\pm 69.4 \mathrm{~g} /$ day; HD-off, $235.2 \pm 37.3 \mathrm{~g} /$ day; $P=0.05)$, which mainly resulted from the increased intake in the dose-reduction group

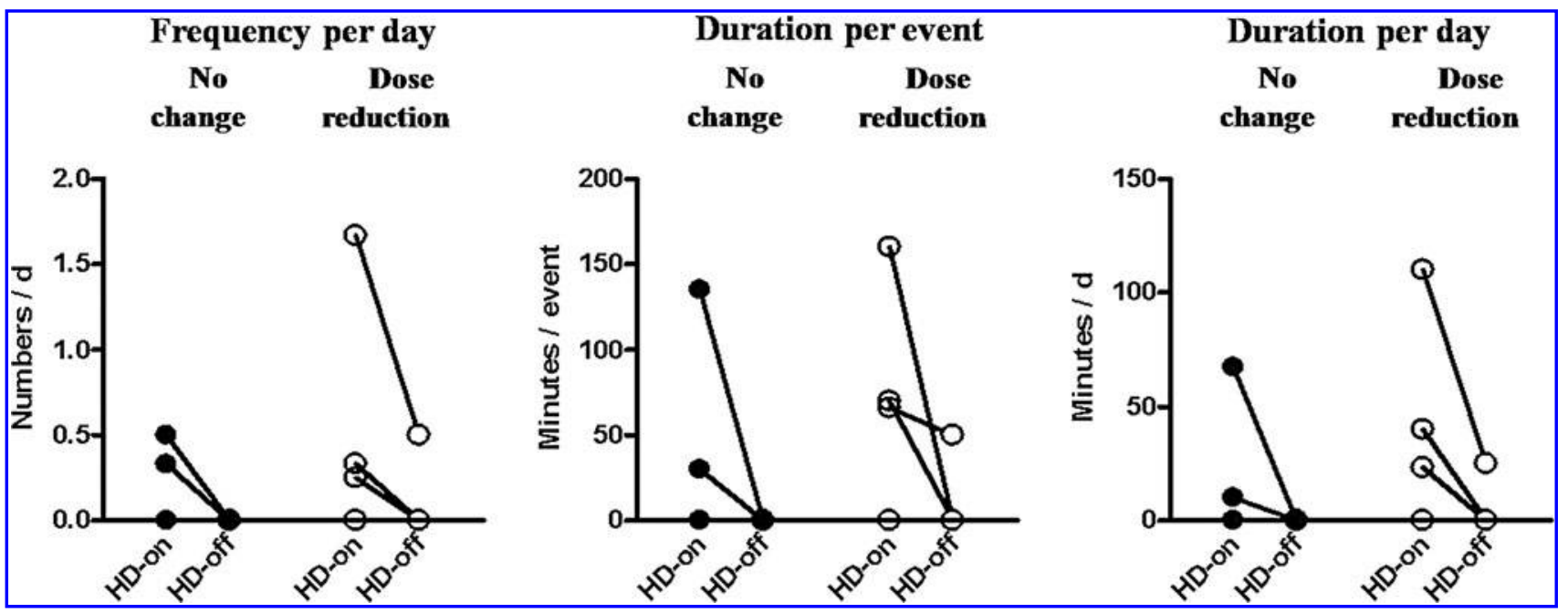

FIG. 3. Frequency and duration of hypoglycemia according to days on and off hemodialysis (HD-on and HD-off, respectively). 


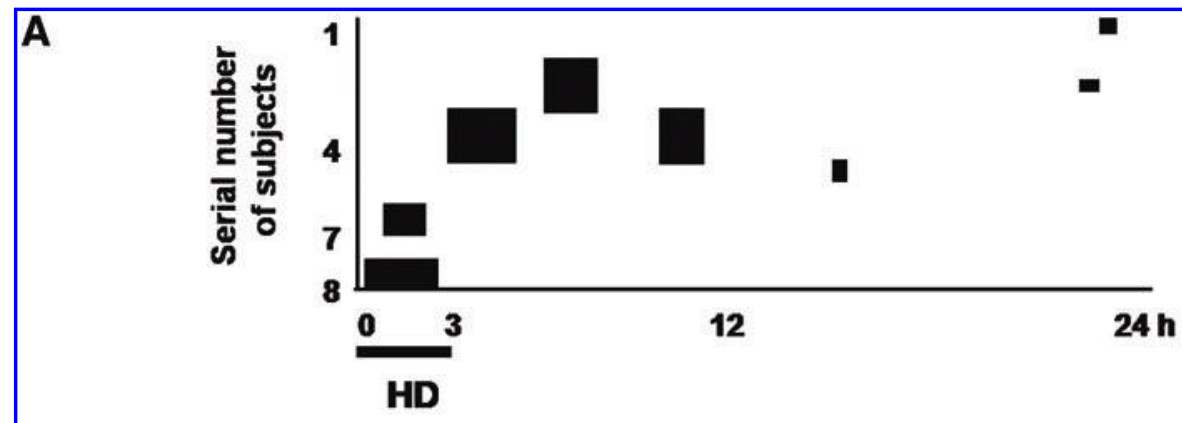

B
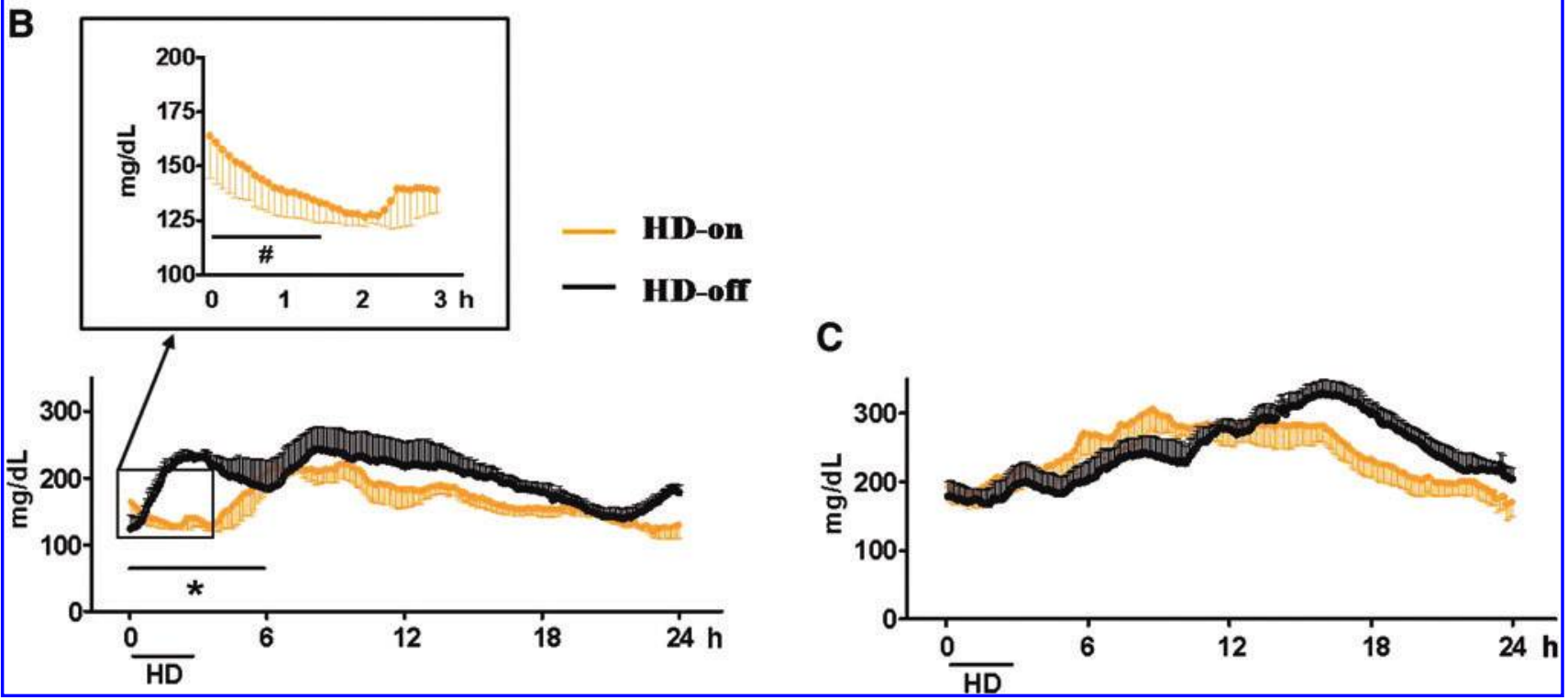

FIG. 4. (A) Duration (width) and severity (height) of hypoglycemia (each rectangle) for day on hemodialysis (HD). (B and $\mathrm{C}$ ) Averaged continuous glucose monitoring readings of the no-change group and the dose-reduction group, respectively. ${ }^{*} P<0.05$ between $\mathrm{HD}$-on and HD-off; ${ }^{*} P<0.05$ within the day on HD. Color image available online at www .liebertonline/dia.

for the days on HD (HD-on, $299.7 \pm 84.3 \mathrm{~g} /$ day; HD-off, $252.3 \pm 47.7 \mathrm{~g} /$ day; $P=0.068)$.

\section{Discussion}

$\mathrm{HbA} 1 \mathrm{c}$ has been known to be a poor marker for mean glucose in patients with ESRD undergoing HD. ${ }^{26-28}$ However, when Riveline et al. ${ }^{16}$ examined it using a GGM system, $\mathrm{HbA1c}$ was significantly associated with mean glucose, although the power was weaker than that in those without nephropathy. In the current study, we reproduced the value of $\mathrm{HbA} 1 \mathrm{c}$ in type 2 diabetes mellitus patients undergoing chronic $\mathrm{HD}$. HbA1c was significantly correlated with mean glucose and MPMG measured by the CGM system for $144 \mathrm{~h}$. In terms of glucose variability, MAGE was not related with mean glucose, $\mathrm{HbA} 1 \mathrm{c}$, and postmeal glucose levels in the subjects, in agreement with a study performed in wellcontrolled type 2 diabetes patients with normal renal function. ${ }^{29}$ According to a recent report, glycemic variability correlated with postprandial $\beta$-cell dysfunction. ${ }^{30}$

Kazempour-Ardebili et al. ${ }^{31}$ reported that mean glucose levels from a CGM system were lower on the day on dialysis than on the day off dialysis. In that study, antidiabetes regimens and calorie intake had not been different according to
HD. However, when we analyzed glucose profiles between HD-on and HD-off, there was no difference. This result could be come from the small sample size for statistical significance because there was a tendency to decrease for mean glucose levels of the day on HD in the no-change group as seen in Figure 2. Therefore, if more patients had been recruited in that group, we could have observed a statistically significant reduction for glucose levels of the day on HD.

The Working Group of the American Diabetes Association defined hypoglycemia as plasma glucose levels $\leq 70 \mathrm{mg} / \mathrm{dL}^{32}$ because the glycemic threshold for activation of glucagon and epinephrine secretion as glucose levels decline was $65-70 \mathrm{mg} /$ $\mathrm{dL}^{33,34}$ and because antecedent plasma glucose levels $\leq 70 \mathrm{mg} / \mathrm{dL}$ reduced sympathoadrenal responses to subsequent hypoglycemia. ${ }^{35}$ However, the threshold for neuroglycopenia seems to be above $70 \mathrm{mg} / \mathrm{dL} .{ }^{36}$ In addition, renal dysfunction and HD are risk factors for hypoglycemia, ${ }^{9,11,37}$ and mild hypoglycemic episodes frequently precede severe hypoglycemia. ${ }^{38}$ Therefore, in this study, we determined hypoglycemia as a CGM reading $<80 \mathrm{mg} / \mathrm{dL}$ for $\geq 20$ min to prevent severe hypoglycemia in the fragile subjects. Despite there being no differences in mean glucose levels and glucose variability between HD-on and HD-off, hypoglycemia usually occurred with day on HD both in the 
no-change and the dose-reduction groups (Fig. 3). Calorie and carbohydrate intakes of the day on HD were larger than those of the day off HD, which reflects the occurrence of more hypoglycemic episodes for day on HD. According to Loipl et al., ${ }^{39}$ hypoglycemic events in insulin-treated type 2 diabetes mellitus assessed by a patient questionnaire occurred at any time during the day on HD, but $33 \%$ of all episodes occurred during or within $3 \mathrm{~h}$ after HD. Using a CGM system, we could observe that most mild hypoglycemia events also occurred during similar periods (Fig. 4A).

There was a significant decrease in glucose levels along with HD in the no-change group (Fig. 4B) as in the study by Riveline et al., ${ }^{16}$ which was not definite in the dose-reduction group. This result suggests that there can be more risk for hypoglycemia during HD if antidiabetes medication is adjusted for days off HD and is not modified for days on HD. In fact, it was not clear if dose reduction affected the glucose reduction during $\mathrm{HD}$ or not, which necessitates evaluation in the same subjects. However, we can speculate that antidiabetes medication would be decreased or not be required just before HD, that hypoglycemia should be monitored more closely during and within some hours after HD, and that glucose levels of the day off HD can be controlled more intensively with lower risk of hypoglycemia because of the need for adequate glycemic control for a better survival rate in diabetes patients with ESRD. ${ }^{4,7}$ For this purpose, we can make use of a CGM system and many kinds of antidiabetes preparations with various action times and biologic half-lives.

\section{Acknowledgments}

This study was supported by a grant from the Korea Science and Engineering Foundation (KOSEF) (0521-20080010) by the Ministry of Education, Science and Technology (MEST), by a grant from the Innovative Research Institute for Cell Therapy (A062260) by the Ministry of Health and Welfare, Republic of Korea, and by WCU project (R31-2008-00010103-0) of the MEST and the KOSEF.

\section{Author Disclosure Statement}

No competing financial interests exist.

\section{References}

1. US Renal Data System. USRSD 2008 Annual Data Report. Bethesda, MD: National Institute of Diabetes and Digestive and Kidney Diseases, 2008.

2. International Diabetes Federation: Diabetes Atlas. Brussels: International Diabetes Federation, 2010.

3. Intensive blood-glucose control with sulphonylureas or insulin compared with conventional treatment and risk of complications in patients with type 2 diabetes (UKPDS 33). UK Prospective Diabetes Study (UKPDS) Group. Lancet 1998;352:837-853.

4. The effect of intensive treatment of diabetes on the development and progression of long-term complications in insulin-dependent diabetes mellitus. The Diabetes Control and Complications Trial Research Group. N Engl J Med 1993;329:977-986.

5. Monnier L, Mas E, Ginet C, Michel F, Villon L, Cristol JP, Colette $\mathrm{C}$ : Activation of oxidative stress by acute glucose fluctuations compared with sustained chronic hyperglyce- mia in patients with type 2 diabetes. JAMA 2006;295:16811687.

6. Wentholt IM, Kulik W, Michels RP, Hoekstra JB, DeVries JH: Glucose fluctuations and activation of oxidative stress in patients with type 1 diabetes. Diabetologia 2008;51:183-190.

7. Drechsler C, Krane V, Ritz E, Marz W, Wanner C: Glycemic control and cardiovascular events in diabetic hemodialysis patients. Circulation 2009;120:2421-2428.

8. Morioka T, Emoto M, Tabata T, Shoji T, Tahara H, Kishimoto $\mathrm{H}$, Ishimura $\mathrm{E}$, Nishizawa $\mathrm{Y}$ : Glycemic control is a predictor of survival for diabetic patients on hemodialysis. Diabetes Care 2001;24:909-913.

9. Haviv YS, Sharkia M, Safadi R: Hypoglycemia in patients with renal failure. Ren Fail 2000;22:219-223.

10. Rigalleau V, Gin H: Carbohydrate metabolism in uraemia. Curr Opin Clin Nutr Metab Care 2005;8:463-469.

11. Jackson MA, Holland MR, Nicholas J, Lodwick R, Forster D, Macdonald IA: Hemodialysis-induced hypoglycemia in diabetic patients. Clin Nephrol 2000;54:30-34.

12. Burmeister JE, Scapini A, da Rosa MD, da Costa MG, Campos BM: Glucose-added dialysis fluid prevents asymptomatic hypoglycaemia in regular haemodialysis. Nephrol Dial Transplant 2007;22:1184-1189.

13. Sangill M, Pedersen EB: The effect of glucose added to the dialysis fluid on blood pressure, blood glucose, and quality of life in hemodialysis patients: a placebo-controlled crossover study. Am J Kidney Dis 2006;47:636-643.

14. American Diabetes Association: Executive summary: standards of medical care in diabetes-2010. Diabetes Care 2010;33:S4-S10.

15. Tamborlane WV, Beck RW, Bode BW, Buckingham B, Chase HP, Clemons R, Fiallo-Scharer R, Fox LA, Gilliam LK, Hirsch IB, Huang ES, Kollman C, Kowalski AJ, Laffel L, Lawrence JM, Lee J, Mauras N, O'Grady M, Ruedy KJ, Tansey M, Tsalikian E, Weinzimer S, Wilson DM, Wolpert H, Wysocki $\mathrm{T}$, Xing D: Continuous glucose monitoring and intensive treatment of type 1 diabetes. N Engl J Med 2008;359:14641476.

16. Riveline JP, Teynie J, Belmouaz S, Franc S, Dardari D, Bauwens M, Caudwell V, Ragot S, Bridoux F, Charpentier G, Marechaud R, Hadjadj S: Glycaemic control in type 2 diabetic patients on chronic haemodialysis: use of a continuous glucose monitoring system. Nephrol Dial Transplant 2009; 24:2866-2871.

17. Kazempour-Ardebili S, Lecamwasam VL, Dassanyake T, Frankel AH, Tam FW, Dornhorst A, Frost G, Turner JJ: Assessing glycemic control in maintenance hemodialysis patients with type 2 diabetes. Diabetes Care 2009;32:1137-1142.

18. Mastrototaro J: The MiniMed continuous glucose monitoring system. J Pediatr Endocrinol Metab 1999;12:751-758.

19. Boland E, Monsod T, Delucia M, Brandt CA, Fernando S, Tamborlane WV: Limitations of conventional methods of self-monitoring of blood glucose: lessons learned from 3 days of continuous glucose sensing in pediatric patients with type 1 diabetes. Diabetes Care 2001;24:1858-1862.

20. Tansey MJ, Beck RW, Buckingham BA, Mauras N, FialloScharer R, Xing D, Killman C, Tamborlane WV, Ruedy KJ; Diabetes Research in Children Network (DirecNet) Study Group: Accuracy of the modified Continuous Glucose Monitoring System (CGMS) sensor in an outpatient setting: results from a Diabetes Research in Children Network (DirecNet) study. Diabetes Technol Ther 2005;7:109-114.

21. Djakoure-Platonoff C, Radermercker R, Reach G, Slama G, Selam JI: Accuracy of the continuous glucose monitoring 
system in inpatient and outpatient conditions. Diabetes Metab 2003;29:159-162.

22. Guerci B, Floriot M, Böhme P, Durain D, Benichou M, Jellimann S, Drouin P: Clinical performance of CGMS in type 1 diabetic patients treated by continuous subcutaneous insulin infusion using insulin analogs. Diabetes Care 2003;26:582589.

23. Diabetes Research in Children Network (DirecNet) Study Group: The accuracy of the CGMS in children with type 1 diabetes: results of the Diabetes Research in Children Network (DirecNet) accuracy study. Diabetes Technol Ther 2003;5:781-789.

24. Service FJ, Molnar GD, Rosevear JW, Ackerman E, Gatewood LC, Taylor WF: Mean amplitude of glycemic excursions, a measure of diabetic instability. Diabetes 1970;19: 644-655.

25. Shim Y, Paik H: Reanalysis of 2007 Korean National Health and Nutrition Examination Survey (2007 KNHANES) results by CAN-Pro 3.0 Nutrient Database. Korean J Nutr 2009; 42:577-595.

26. Nakao T, Matsumoto $H$, Okada $T$, Han $M$, Hidaka $H$, Yoshino M, Shino T, Yamada C, Nagaoka Y: Influence of erythropoietin treatment on hemoglobin A1c levels in patients with chronic renal failure on hemodialysis. Intern Med 1998;37:826-830.

27. Morgan L, Marenah CB, Jeffcoate WJ, Morgan AG: Glycated proteins as indices of glycaemic control in diabetic patients with chronic renal failure. Diabet Med 1996;13:514-519.

28. Williams ME, Lacson E Jr, Teng M, Ofsthun N, Lazarus JM: Hemodialyzed type I and type II diabetic patients in the US: characteristics, glycemic control, and survival. Kidney Int 2006;70:1503-1509.

29. Kohnert KD, Augstein P, Heinke P, Zander E, Peterson K, Freyse EJ, Salzsieder E: Chronic hyperglycemia but not glucose variability determines $\mathrm{HbA1c}$ levels in wellcontrolled patients with type 2 diabetes. Diabetes Res Clin Pract 2007;77:420-426.

30. Kohnert KD, Augstein P, Zander E, Heinke P, Peterson K, Freyse EJ, Hovorka R, Salzsieder E: Glycemic variability correlates strongly with postprandial beta-cell dysfunction in a segment of type 2 diabetic patients using oral hypoglycemic agents. Diabetes Care 2009;32:1058-1062.

31. Kazempour-Ardebili S, Lecamwasam VL, Dassanyake $T$, Frankel AH, W.K. Tam F, Dornhorst A, Frost G, J.O. Turner $\mathrm{J}$ : Assessing glycemic control in maintenance hemodialysis patients with type 2 diabetes. Diabetes Care 2009;32:11371142.

32. American Diabetes Association Workgroup on Hypoglycemia: Defining and reporting hypoglycemia in diabetes: a report from the American Diabetes Association Workgroup on Hypoglycemia. Diabetes Care 2005;28:1245-1249.

33. Mitrakou A, Ryan C, Veneman T, Mokan M, Jenssen T, Kiss I, Durrant J, Cryer P, Gerich J: Hierarchy of glycemic thresholds for counterregulatory hormone secretion, symptoms, and cerebral dysfunction. Am J Physiol 1991;260:E67E74.

34. Schwartz NS, Clutter WE, Shah SD, Cryer PE: Glycemic thresholds for activation of glucose counterregulatory systems are higher than the threshold for symptoms. J Clin Invest 1987;79:777-781.

35. Davis SN, Shavers C, Mosqueda-Garcia R, Costa F: Effects of differing antecedent hypoglycemia on subsequent counterregulation in normal humans. Diabetes 1997;46:1328-1335.

36. De Feo P, Gallai V, Mazzotta G, Crispino G, Torlone E, Perriello G, Ventura MM, Santeusanio F, Brunetti P, Bolli GB: Modest decrements in plasma glucose concentration cause early impairment in cognitive function and later activation of glucose counterregulation in the absence of hypoglycemic symptoms in normal man. I Clin Invest 1988;82:436-444.

37. Cryer PE, Davis SN, Shamoon H: Hypoglycemia in diabetes. Diabetes Care 2003;26:1902-1912.

38. Kovatchev BP, Cox DJ, Farhy LS, Straume M, GonderFrederick L, Clarke WL: Episodes of severe hypoglycemia in type 1 diabetes are preceded and followed within 48 hours by measurable disturbances in blood glucose. J Clin Endocrinol Metab 2000;85:4287-4292.

39. Loipl J, Schmekal B, Biesenbach G: Long-term impact of chronic hemodialysis on glycemic control and serum lipids in insulin-treated type 2-diabetic patients. Ren Fail 2005; 27:305-308.

Address correspondence to: Kyong Soo Park, M.D. Department of Internal Medicine Seoul National University College of Medicine 28 Yongon-dong Chongno-gu, Seoul 110-744, Republic of Korea

E-mail: kspark@snu.ac.kr 

This article has been cited by:

1. M. Nowicki, I. Rychlik, H. Haller, M. Warren, L. Suchower, I. Gause-Nilsson, K-M. Schützer. 2011. Long-term treatment with the dipeptidyl peptidase-4 inhibitor saxagliptin in patients with type 2 diabetes mellitus and renal impairment: a randomised controlled 52-week efficacy and safety study. International Journal of Clinical Practice no-no. [CrossRef] 